\title{
Entrevista: Serge Alecian e Dominique Foucher É preciso aprender a transgredir
}

Edição: Claudia A sazu

Gerenciar, definem os consultores franceses Serge Alecian e Dominique Foucher, consiste em conduzir um grupo de pessoas para atingir, em comum, as metas da organização. A definição, aparentemente simples,

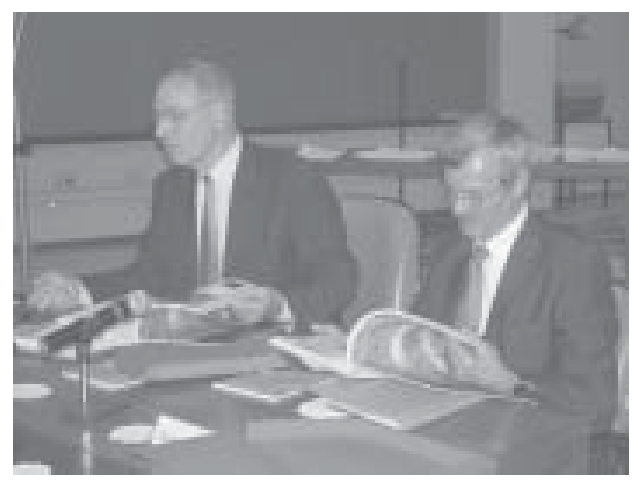
impõe um grande desafio. D irigentes públicos não recebem formação para exercer as funções de gerenciamento e o resultado, muitas vezes, traduz-se na tendência de se refugiar no tecnicismo. "Há os que apenas se comportam como chefes, que acabaram de sair da escola e são colocados em postos de chefia, porque são inteligentes. Mas esses se encontram em situação de chefia, não de gerenciamento. E sem gerenciamento, não há resultados", diz Alecian. Cada gerente deve desenvolver o seu próprio estilo, mas há características comuns a todo gerenciamento bem-sucedido: coerência, coragem, clareza e consideração - a Regra dos 4C. É preciso também, ressalta Foucher, ousar, ir além das normas, transgredi-las, mantendo-se, por outro lado, leal aos superiores hierárquicos. Autores do G uia de gerenciamento no setor públion (Revan/ ENAP, 2001) ${ }^{1}$, Alecian e Foucher atuam na Société Innovence, empresa de consultoria em gerenciamento 
e gestão de recursos humanos para os quadros dirigentes do serviço público francês e de diversos outros países, bem como para os de empresas privadas.

Da Redação - C omo gerenciar bem equipes, tornar-se um gerente competente?

Dominique Foucher - É preciso, sobretudo, pensar o exercício do gerenciamento não simplesmente como respeito à hierarquia. É necessário liberdade de expressão em relação ao superior hierárquico. Assim, creio que o primeiro critério para ser um gerente competente, que não é freqüentemente colocado, é ser leal ao chefe, mas nunca ser-lhe submisso ou servil. Creio que essa seja uma dificuldade para alguns gerentes. Esse critério me parece mais relevante do que aqueles mais comumente levantados, como a capacidade de fixar objetivos, de mobilizar equipes, de atuar como líder, de saber avaliar os resultados. Aquele primeiro critério pode não ser o mais importante, mas, sem ele, as demais capacidades se inviabilizam. 0 que, por exemplo, se aprende nos livros é que o gerenciamento por objetivos ${ }^{2}$ requer capacidade de discutir e eventualmente negociar com o superior hierárquico não sobre os objetivos porque esses são estabelecidos pelo superior - , mas sobre a forma de realizálos, sobre os prazos e os insumos necessários. $\mathrm{O}$ u seja, a lógica aqui é a da responsabilização e não a da execução. Mas, ora, para que eu seja de fato responsável pelo que me foi confiado, é preciso que eu tenha liberdade de expressão com relação a meus superiores e espírito crítico.

Da Redação - E como se aprende a ser um gerente competente?

Serge Alecian - Gerenciar é uma prática, uma atividade, uma profissão e, como tal, se aprende na prática. Não se aprende na escola, em um curso ou em um seminário. Tudo isso éimportante, mas não substitui a prática. Portanto, voltando à questão "como se aprende a ser um gerente competente?", é colocando os gerentes em posição de gerenciar em diferentes situações. Não pense que eles serão grandes chefes de imediato, pelo contrário. Há os que apenas se comportam como chefes, acabaram de sair da escola e são colocados em postos de chefia, porque são inteligentes. Mas esses se encontram em situação de chefia, não de gerenciamento. Eles dão ordens e acreditam que isso basta. Portanto, é preciso, o mais rápido possível, colocá-los em diferentes postos de gerenciamento, para que aprendam na prática. A gestão de recursos humanos, nesse sentido, éessencial para fazê los mudar de área, organizar a mobilidade em função do interesse da administração pública e não simplesmente em função da necessidade profissional do indivíduo. É preciso também que haja alternância entre formação e ação. A ENA (École Nationale d'Administration) ${ }^{3}$ oferece uma formação excelente em nosso país. 0 que acontece, porém, é que, mesmo com essa formação fantástica, temos um setor público que tem perdido, pouco a pouco, sua qualidade. Éramos o primeiro do mundo e hoje não passamos do segundo ou terceiro. É preciso prática. Na França, deixamos os gerentes, um ano ou um ano e meio, em um mesmo posto - dizem que permanecer maistempo os "emburrece", mas o fato é que eles não conseguem fazer nada nem aprender nada nesse curto período.

Da Redação - Trata-se, então, de tentativa e erro?

Serge Alecian - Certamente. Aprendemos com os erros, com as situações, compreendendo a estrutura da organização . 
Na França, e creio que sejaum pouco assim também no Brasil, os servidores formamse em grandes escolas e já começam por cima, ocupando altos cargos. Eles não sabem como funciona a estrutura da organização e tomam decisões que não levam em conta a realidade dela. Trabalhamos, por exemplo, com os formandos da ENA, uma escola de elite, de ponta. $O$ problema é que gerenciamento não diz respeito apenas a uma questão de inteligência. Para torná-los gerentes competentes, é melhor lançá-los à prática, mas não fazendo-os começar de cima. Antes, um servidor iniciava sua carreira em um posto operacional. O mesmo ocorria nas empresas privadas: um diretor de banco começava seu aprendizado no guichê. Hoje, eles se tornam, de imediato, diretores ou vice-diretores, o que gera um problema sério. Há ênfase sobre ainteligência e não sobre outras qualidades do gerente, como a coragem, que se aprende na prática. Não quero dizer com isso que a formação não é importante, mas é necessário refletir sobre ela tendo em mente as necessidade dos diferentes órgãos da administração pública, em articulação com a gestão de RH, e ter como meta, também, a mobilidade. O sistema, na França, funciona de maneira tal que os servidores são promovidos de imediato, sem experiência. São eles, sem dúvida, a nata dos graduados, saem das melhores escolas francesas. Quando lhes ministramos cursos sobre gerenciamento, eles compreendem o assunto perfeitamente, porque não se trata de algo difícil de se compreender, trata-se de bom senso. Eles logo se desinteressam. Entretanto, quando retornam ao curso, um ano depois, já atuantes, os mesmos alunos trazem cem dúvidas para resolver em sala de aula. Ou seja, não é uma questão de compreender, é uma questão de agir, pôr em prática.
Da Redação - M as como evitar o risco de práticas desastrosas?

Serge Alecian - A possibilidade de desastre está em todo lugar. Pensa-se que, no setor privado, existe o direito de errar. Não parece tão grave errar no setor público, porque o erro nunca, ou quase nunca, é punido. Quando eu erro, por um dia, a entrega da minha declaração de imposto, tenho de pagar $10 \%$ de multa. Mas, quando um servidor público não me responde ou comete um erro, nada ocorre. Então, não faz sentido temer desastres. Além disso, colocando-os em postos de

primeiro nível, eles estarão sob a direção de alguém mais experiente, que vai impedir os erros. É por isso que eles deveriam começar em departamentos pequenos, por baixo. Mas não é o que ocorre na França, eles são logo enviados para postos de direção. Lá, eles podem cometer erros, embora se trate de pessoas sérias, que trabalham 70 horas por semana para evitálos. É um sistema elitista, porque pressupõe que apenas aqueles "de cima” podem errar, o que é mais grave. Entrega-se um posto a um jovem de 27 anos, que irá trabalhar com pessoas de 50 anos, e são 
estes últimos que fazem a administração andar para frente. Na França, há grande admiração, uma espécie de veneração, por esses jovens. Eu dizia que não é grave errar na administração pública, e, de fato, não é. Mas, ao cabo de 15 anos assim, toda a administração está desmantelada. No passado, tratava-se de fazer funcionar um sistema taylorista. Nele, a troca de um chefe incompetente pouco importava, porque 0 sistema caminhava sem ele, era feito para andar sozinho. Hoje, porém, demanda-se o "sob medida", a adaptabilidade, a mobilidade, e o papel do gerente torna-se essencial. Sem gerenciamento, não há resultados.

Dominique Foucher - O sistema é incontestavelmente "bem-feito" para esses jovens brilhantes. São servidores formados em grandes escolas - aos quais se reservam unicamente os cargos de grande responsabilidade -- rodeados de colaboradores excelentes. Na verdade, são eles, os colaboradores, que os formam. Se ocorrem erros técnicos, lá estão os colaboradores para corrigi-los. E, se há erros de gerenciamento, é triste dizer, os colaboradores estão acostumados. São pessoas que sabem que irão formar o gerente recém-chegado e, quando este estiver pronto, haverá outros novos. É um modo de gestão que busca pôr as pessoas na prática para formá-los, mas, por outro lado, extremamente elitista. Um determinado número de carreiras intermediárias reclama que está, dessa forma, condenada à própria sorte.

Serge Alecian - É um problema. $\mathrm{Na}$ Alemanha, por exemplo, os cargos de direção públicos e privados são ocupados por pessoas que ascenderam na carreira. D os dirigentes, $70 \%$ são pessoas que começaram em baixo e foram promovidas. Na França, é o contrário: $80 \%$ já começaram por cima. São servidores que, desde sua posse, ouvem dizer que são da elite, são inteligentes, etc. Mas, para gerenciar, o que conta é a regra dos $4 \mathrm{C}$, sobretudo a coragem. E isso não se

\section{A regra dos $4 \mathrm{C}$ do gerenciamento}

C oerência

- entre as palavras e atos: prometer mudanças e nada decidir nesse sentido, pedir respeito aos horários e começar reuniões com atraso, dizer que o direito de errar existe, mas aplicar sanção àquele que erra, etc. são atitudes incoerentes; - das decisões em si: tomar decisões opostas no decurso do tempo, aceitar o erro de um e não de outro, etc. também mostram incoerência;

- entre os objetivos estabelecidos e os meios destinados a eles: alocar recursos em função de prioridades claramente estabelecidas.

C oragem:

- para tomar decisões: decidir é renunciar, dizer o que não se quer;

- para despender esforços e resistir ao desgaste da decisão;

- para resistir à pressão psicológica e moral no sentido de ver questionada a decisão; é preciso também "confrontar" os colaboradores, dizer 0 que está bem e o que não está.
Clareza:

- esclarecer as metas da organização e a regra do jogo;

- precisar os objetivos a alcançar, as opções estratégicas e os obstáculos;

- comunicar, de maneira regular, os resultados das decisões tomadas, buscando um grau de transparência ótimo e o estabelecimento de uma relação de confiança entre o gerente e os colaboradores.

Consideração:

- pelos colaboradores com atenção, escuta, respeito: respeitar seus problemas e dificuldades, perguntar-lhes sobre suas preocupações, etc.; - pelo trabalho deles: evitar manifestação de desprezo por um trabalho pouco valorizado, mostrar sempre reação ao trabalho trazido, marcar positiva ou negativamente os esforços ou falhas, etc.;

- pelas idéias e propostas trazidas: levar em consideração e divulgar as idéias de colaboradores.

Fonte: Alecian, Serge; Foucher, D ominique. G uia do gerenciamento no setor público 
aprende na escola, pelo contrário. Lá, as provas são "anticoragem", é preciso fazer um plano bem equilibrado, ponderado, moderado, etc. Na teoria, isso funciona, mas, na prática...

Da Redação - Falamos sobre a cragem e gostaríamos de falar agora sobre a compreensão. Como formar gerentes que tenham oragem para tomar decisões, de manterem-se leais em relação a seus superiores, mas sem serem submissos ou servis e, ao mesmo tempo, tenham a capacidade de compreender que cada pessoa tem problemas reais que podem comprometer sua atuação œmo servidor? É, sem dúvida, um problema de gerenciamento, mas que somentea prática pode não ser suficiente...

Serge Alecian - D e fato, é necessário fazer um acompanhamento por meio de cursos de formação complementar, principalmente no que toca à compreensão. É preciso aprender a discernir quando as pessoas não querem e quando não podem, 0 que muitas vezes os gerentes desconhecem ou sobre o que faz em confusão. E talvez aqui haja um trabalho a ser feito com psicólogos, sociólogos, etc. e entre os dirigentes mesmos. Há aí certamente um aprendizado que tem de ser feito, principalmente no serviço público. Quando as pessoas não podem, não podemos abandonálos, é preciso fazer o trabalho junto. Para compreender as pessoas, deve-se levar em conta a dimensão humana. $\mathrm{O}$ que ocorreu em todas as culturas do serviço público é a neutralização do fator humano, em razão do temor de companheirismo, da preferência, das "costas quentes". Tudo foi "objetivado": o recrutamento mediante concurso, a progressão por antigüidade, a proibição de diferenças remuneratórias.. as pessoas se sentem incomodadas com isso e há um imenso trabalho a fazer. Não para que esses critérios desapareçam - é bom que métodos objetivos existam - ,

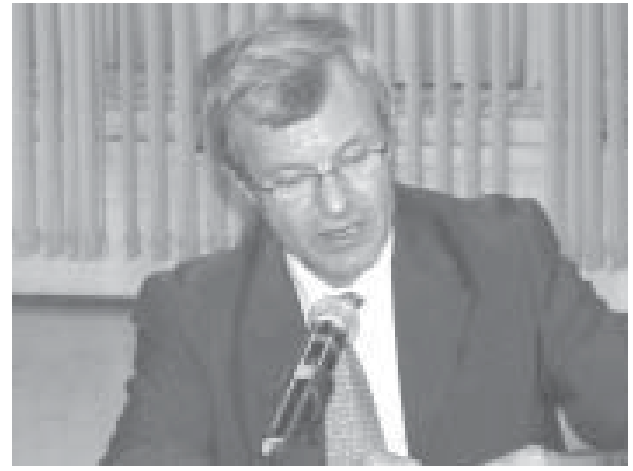

mas para que a dimensão humana seja também levada em consideração. Isso é gerenciamento. A formação dos gerentes deveria incluir também a compreensão dos problemas das pessoas. Há pessoas que nem sequer se dão conta de seus comportamentos em relação aos outros. É preciso, portanto, colocar os gerentes em situação de gerenciar e envolvê-los em formação continuada e regular. Creio que, na Alemanha, no Reino Unido, nos EUA e em nosso país, isso começa a se desenvolver, passamos a trabalhar mais e mais com a alternância entre formação e prática.

Da Redação - H á uma tensão permanente entre a criatividade e a atuação na administração pública, sobretudo no nível federal, porque há servigos que devem ser realizados em longo prazo, que não podem mudar de imediato. C omo lidar com essa tensão?

Serge Alecian - Não sei falar disso sem chocar, mas, como diz D ominique, é preciso não trair, mas recolocar em questão 0 acordo. Não ousamos ir longe, mas isso é realmente um problema, porque, se não somos capazes de sair do caminho, jamais descobriremos algo novo. Ao mesmo tempo, o servidor deve ser leal. A questão é : como ser leal e aprender a transgredir uma regra? Não saber transgredir é muito perigoso, assim como não fazer nada além de transgredir também o é. Às vezes, na 
função pública - na verdade, não somente nela -, nós formatamos as mentes de maneira que todos pensem de forma igual. Isso me dá medo, porque assim desaparecem os cérebros As pessoas passam a não se comportar por elas mesmas, é 0 melhor dos mundos de Aldous Huxley. Tornamo-nos todos parecidos, clones.

Da Redação - A estrutura da administração pública não estimula a inovação. N o entanto, vemos a inovação ocorrer, vemos que há inovadores. Como dar maior espaco para que ela ocorra?

Serge Alecian - É novamente a arte de 0 gerente conseguir um equilíbrio entre a capacidade de fazer, de agir, de um lado, e a de ir além das regras, de outro. Também aqui há uma formação a ser dada para explicar-lhes que as regras são necessárias, os procedimentos são necessários, mas também é preciso saber contomá-los, por vezes, ou seja, é preciso também ensiná-los a transgredir, ao mesmo tempo que lhes incutimos valores para evitar "derrapagens".

Da Redação - É preciso coragem.

Serge Alecian - Sim, voltamos à coragem. Por outro lado, há, de fato, criatividade no serviço público. Por quê? Porque há muitas pessoas que ingressam no serviço público por conviç̧ão, porque querem servir à coletividade, porque consideram a função pública nobre. Repito: é preciso aprender a transgredir. 0 sistema público é reducionista, ele "corta cabeças", corta a coragem. Se queremos criatividade, devemos, em primeiro lugar, aceitar que as pessoas assumam riscos, saiam dos procedimentos Em geral, é o contrário: lembra mo-lhes incessantemente que há procedimentos a serem seguidos. Em segundo lugar, se há pessoas que transgridem e assumem riscos, há também pessoas que erram. Nesse sentido, a questão é saber como o direito ao erro é tratado. É necessário tratar de forma positiva a tentativa mal-sucedida que tenha sido de boa-fé. Nesse ponto, vejam os norte-americanos: mesmo que a pessoa tenha falhado, se não o fez desonestamente, considera-se que ela tenha aprendido algo. Em nosso país e possivelmente no Brasil, reprovamos a iniciativa, porque ela foi falha na primeira tentativa. Mas só aprendemos fazendo erros... Em terceiro lugar, avaliar como tratamos aqueles que não fazem nada e, assim, não erram. Infelizmente, em geral, são esses que fazem carreira. Não erram nunca, ou seja, são os "não-criativos", mas os únicos promovidos. Se esses três aspectos forem observados, teremos, então, criatividade.

Da Redação - Se sou um colaborador e tenho um chefe que não observa a regra dos 4C, como devo comportar-me, como deve ser meu relacionamento com 0 chefe? M udar de posto seria o ideal?

Dominique Foucher - Não. Seria preciso, primeiro, que houvesse a possibilidade de mudança de posto, já que, com ela, a "relação de força" se modifica e se torna possível conversar com o chefe. Mas isso é raro. Convém, assim, distinguir 0 ideal do real. 0 ideal é intervir junto ao superior hierárquico e dizer-lhe que as coisas não estão bem. A experiência mostra que, de dez superiores hierárquicos, ao menos seis irão aceitar as críticas dos colaboradores, sob a condição de que eles saibam fazê-lo (mostrando-se leais, respeitando a linha hierárquica, evitando ataques pessoais, etc.). É mais difícil com os outros quatro, aqueles que não querem ouvir nada, que consideram toda crítica um "crime de lesa-hierarquia". Com esses, 0 colaborador não tem exatamente opções, é melhor preparar sua partida. 
Da Redação - D izemos, no Brasil, que, quando os chefes não onseguem conversar com suas equipes, ex ercese, às vezes, um "poder de veto". Os chefes pensam queestão dando ordens, mas nada se produz efetivamente. E vita-se 0 confronto e, assim, é mais fácil não fazer nada e dar a impressão de que se está fazendo. Isso é bastantenegativo para a administração pública. Como éna França?

Dominique Foucher- Na França, há uma estratégia de arregaçar as mangas. Quando um chefe não faz o que deve ou não é apreciado, os colaboradores adotam uma estratégia de inércia. Não fazem nada ou somente fazem o mínimo, o que não é o mesmo que exercer um direito de veto. Com ele, eu manifesto minha discordância. Com a estratégia de inércia, eu não a digo abertamente. E uma estratégia que não é muito corajosa, ela alimenta a inércia no conjunto do sistema. Há também, em outra ponta, aqueles que vão sistematicamente ao conflito. Confrontam-se por falta de tato e cometem erros. Assim, não fazem o sistema andar para frente.

Da Redação - V oltamos à questão da formação. Ter uma boa formação acadêmica é ter tido a sorte de ter uma família com meios de financiá-la. É preciso, entretanto, formar também pessoas que consigam reconhecer outras formas de inteligência e de conhecimento, para que haja intercâmbio entre elas Caso contrário, o serviço público não irá avançar e creio que 0 mesmo aconteça no setor privado. Por outro lado, não podemos apenas depender de colaboradores de 50 anos, generosos.

Serge Alecian - É verdade que, nas empresas, isso existe ainda, embora, com a globalização, 0 aumento da competitividade, etc., elas tenham reduzido drasticamente seus quadros. Eu estive no Reino Unido, onde os bancos reduziram em um quarto os seus quadros nos últimos quatro, cinco anos. Hoje, há um terço a menos de pessoas do que há 15 anos. D ois elementos essenciais para avançar são a gestão de recursos humanos e a formação, e chegamos aqui ao cerne do problema, um problema de competências: como adquirilas, como passá-las, como faz er mudanças. Há ainda um problema: além da administração, há o político. É preciso que a esfera política também faça seu trabalho. Não sei como é no Brasil, mas, na França, um dos problemas é que o político não faz o seu

"O gerente deve preocupar-se com os resultados de seu gerenciamento e não limitar a avaliação de seu desempenho unicamente em razão do resultado obtido, pois 0 elo entre $o$ resultado e a qualidade do gerenciamento não é imediato."

trabalho: remete-o à administração, à tecnocracia, que, por sua vez, não sabe gerir problemas politicamente e não o faz. Eu particularmente acho que não há pensamento político novo há 30, 40 anos. Os políticos fogem de suas responsabilidades. Se as prioridades, que só podem ser definidas politicamente, são definidas pela administração, algo vai mal.

Da Redação - 0 sr. diz que um negociador devedesconfiar de si mesmo 0 gerente também deve desconfiar de si mesmo?

Dominique Foucher- 0 negociador deve desconfiar de si mesmo, de suas 


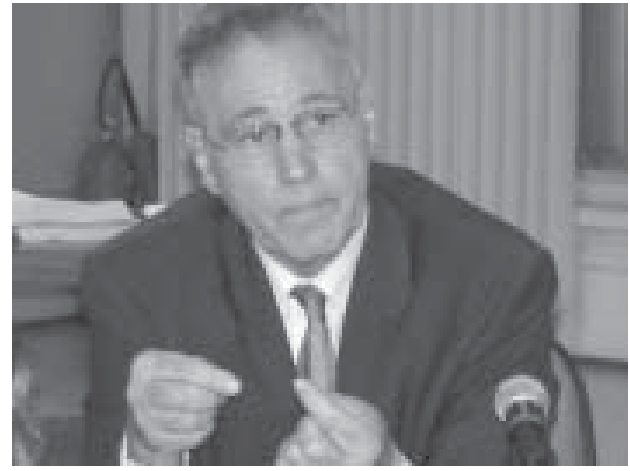

habilidades ${ }^{4}$, a partir de uma análise rápida da situação, lembrando-se de situações anteriores que ele tenha enfrentado. 0 gerente competente deve preocupar-se em saber quais os efeitos, os ecos, os resultados, a eficácia de seu gerenciamento e não limitar a avaliação de seu desempenho unicamente à medida do resultado obtido. Por quê? Porque o elo entre o resultado e aqualidade do gerenciamento não é imediato, o que é particularmente verdadeiro no serviço público. Constatamos, por exemplo, casos de gerentes que obtiveram resultados excelentes de suas equipes e, no entanto, 0 seu gerenciamento não era bem visto nem pelos colaboradores nem pelos superiores. Curioso, não? Isso significa que basta ter colaboradores motivados - o que não é raro na função pública - para se chegar aos resultados, ainda que o gerenciamento seja falho. Nesse sentido, seria útil para um gerente ter em mente os efeitos de seu gerenciamento, não porque ele está preocupado com a sua imagem, o que não deixa de ser importante, mas, sobretudo, porque há preocupação na eficiência. Ou seja, perguntar-se: "Tenho feito o que é preciso para obter o resultado?" E como fazer isso? Utilizando alguns instrumentos e construindo outros. Um deles éatentar para que, a cada mês, haja, na ordem do dia das reuniões, uma análise mais solta, livre, sobre a maneira como o trabalho vem sendo gerenciado. Um outro seria adotar um dispositivo de "vigilância" social, algo mais construído, que consiste em um sistema que concilia osindicadores de gestão de RH com minienquetes sobre o clima de trabalho e com o conjunto de informações reunidas dos colaboradores e dos próprios gerentes. $\mathrm{Na}$ Alemanha, a Bundesakademie adota mecanismos de avaliações sistemáticas dos gerentes por suas equipes. Elas são sempre anônimas e são necessárias, pelo menos, cinco pessoas. Elas sobem à Diretoria de $\mathrm{RH}$, que, por sua vez, repassam-nas ao superior hierárquico, dizendo: "Bom, aqui estão os resultados. Em 15 dias, diga-nos 0 que seráfeito". Se nesse período não houver resposta, a D RH intervém novamente. Permanecendo ruim a avaliação depois de seis meses, aD RH faz um coaching, um treinamento em nível de gerência para ajudar esse gerente a corrigir o que vai mal. É algo bastante constrangedor, que, às vezes, seduz os quadros gerenciais franceses e, às vezes, os irrita. Mas, na Alemanha, a idéia é que, se uma reformaénecessária, épreciso primeiro mudar o comportamento dos chefes, sob risco de não ser bem-sucedido. Assim, eles se preocupam verdadeiramente com os chefes e com o gerenciamento. Há também os instrumentos mais clássicos, que se propagam. Um exemplo: interrogar os colaboradores e outros interlocutores (superiores hierárquicos, colegas, etc.) sobre o gerenciamento, fazendo alusão à avaliação $360^{\circ}$. Por fim, creio que uma boa maneira de o gerente desconfiar de si mesmo ou, mais precisamente, de preocupar-se em progrediré sair, buscar formação fora. Essa formação pode-se dar em um lugar, mas pode ser um autoquestionamento, um exercício de recolocar-se em questão. G osto muito da idéia de se questionar durante 0 período de formação, fazendo com que 0 gerente tenha possibilidade de trabalhar com 
pessoas que não sejam de seu serviço e não se conheçam. Isso facilita o questionamento, tendo em vista que, com pessoas que conhecemos, ativamos a nossa lógica de autoproteção.

Da Redação - Para que esse tipo de avaliação seja sistemática, é essencial o papel da D RH . Q uais os desafios das D RH s no setor públio?

Serge Alecian - Tornar a gestão de recursos humanos uma função compartilhada entre a D RH e os gerentes. A gestão de RH deveria ser feita com a participação deles. É o que vemos hoje nas empresas. 0 desafio maior, portanto, é tentar reformarse. As D RHs dirão que a mudança não depende delas, mas de estatuto, do sindicato, do Ministério da Fazenda, etc. e todos passam a bola para o outro. Mas o desafio está lá. Para conseguirmos alocar as competências para o lugar certo e no momento certo, deve-se, fundamentalmente, envolver mais o gerenciamento na gestão de $\mathrm{RH}$, talvez não desde o início, no momento do recrutamento, já que há concursos, mas na escolha de pessoas com base na lista de aptidões, na gestão da mobidade, da remuneração, da formação, dos treinamentos e na atuação dos servidores. Os verdadeiros desafios estão aí. O Grupo Accor faz isso na Espanha e em outros países. São os funcionários de cada hotel que gerenciam e fazem a gestão de RH.

Da Redação - N os hospitais também, a enfermeira ex erce um papel muito forte de gestão de recursos humanos.

Serge Alecian - Mas não é a tradição no serviço público, e esse é o grande desafio.

Da Redação - A s novas tecnologias de informação podem ajudar nesseprocesso, elas abrem possibilidades maiores.
Dominique Foucher - À condição que tais instrumentos sejam de fato colocados à disposição para esse fim. Do contrário, as novas tecnologias permitem também conceber a D RH não mais como área estratégica, mas como área meio, que se colocaà disposição dos gerentes para que eles possam recrutar e gerenciar os colaboradores de acordo com regras definidas e exigir de cada um deles que se gerenciem. É o que chamamos na França de "empregabilidade". Não sei se é um desafio, mas, em todo caso, é uma evolução. Em algumas atividades, notadamente no setor privado, há a idéia de que a cada um cabe gerenciar a sua própria carreira. A empresa não está lá para gerir as carreiras das pessoas, mas para facilitar e a ajudá-las nessa tarefa. É uma abordagem possível, na qual as novas tecnologia são bastante utilizadas. Há outras abordagens que "tomam conta" sistematicamente dos profissionais. Nessa lógica, as pessoas evoluem progressivamente e há acumulação e capitalização de experiência. Sem dúvida, no serviço público francês, essa função terá de ser compartilhada e não centralizada, de maneira que a trajetória profissional seja repensada por todos e não simplesmente por alguns. Ressalto que estatutos não são um problema em si. O s relatórios Valmont, de 1998, e de Pochard, de 2003, dois trabalhos importantes para se compreender a evolução da função pública na França, mostram bem esse aspecto. Valmont diz que estatutos são positivos, porque criam uma identidade cultural. O que é problemático é o uso que fazemos deles.

Da Redação - H á alguma particularidade brasileira no gerenciamento, comparando-0 com o modo franôs?

Serge Alecian - Parece-me, baseado nas leituras que fiz sobre o Brasil, que aqui 
não se aprecia 0 confronto, adotam-se estratégias para contorná-lo. Isso nos intriga porque, lendo Sérgio Buarque de Hollanda, vemos o brasileiro definido como um aventureiro, um senhor de si mesmo, que não gosta de receber ordens, que gosta da liberdade, etc. Temos a impressão de que se trata de valores da aristo cracia passada, que continuam presentes, ainda que esquecidos durante o período militar. Entretanto, parece-me que as pessoas são bastante hierárquicas ainda, o que dificulta a condução de mudanças. Uma parte da população não quer o conflito, prefere obedecer, ser dirigido. Ao mesmo tempo, os dirigentes não se podem comportar como antes, de forma autoritária. Há, assim, um modo de dirigir, que é de evitar 0 confronto e de negociar, talvez com alguma dose de manipulação. E é um modo também hierárquico. Não se diz nada diretamente, mas por rodeios. 0 brasileiro é mais um homem cordial do que um homem educado. A educação nos permite manter a distância, mas a cordialidade a reduz. Isso resulta em um modo de gerenciamento. As pessoas dizem bom-dia sempre, batem nas costas, mesmo sendo de níveis hierárquicos muito diferentes, ainda que saibam exatamente quem manda e quem não manda. Nesse contexto, há somente espaço para negociar, e negociação produz um acordo, mas não necessariamente eficácia. É preciso negociar e gerenciar, não fazer um ou outro.

\section{Notas}

${ }^{1}$ Fonte: Alecian, Serge; Foucher, D ominique. G uia do gerenciamento no setor público. Rio de Janeiro: Revan; Brasília: ENAP, 2001.

${ }^{2}$ Ver, por exemplo, Bollinger, D; Hofstede, G. Les différences culturelles dans le management: comment chaque pays gère-t-il ses hommes? Paris: Les Editions d'O rganisation, 1987.

${ }^{3}$ A ENA recruta e forma os altos funcionários da administração central francesa.

${ }^{4}$ Foucher sugere uma tipologia de negociador, baseado em suas características e combinações. Existe o manipulador, que esconde o jogo; o honesto, que coloca todas as cartas na mesa; o lúcido, que vê claramente o jogo do outro e leva isso em consideração; e o ingênuo, que não se preocupa com o jogo do outro e se deixa enganar. A combinação entre o lúcido e o manipulador resulta em um negociador "maquiavélico", para quem só os resultados importam. Do manipulador e do ingênuo, surge um "jogador", que considera que os outros são fáceis de ganhar. 0 ingênuo e o honesto formam uma "criança no coral", ou seja, um negociador que vê todos como pessoas honestas como ele. A combinação entre o honesto e o lúcido forma o "realista", aquele que busca tornar possível o que é necessário. 